\title{
A case of Arnold-Chiari syndrome with flaccid paralysis and huge syringomyelia
}

\author{
T Mimura*, ${ }^{*}$ S Asajima ${ }^{1}$, Y Saruhashi ${ }^{1}$ and Y Matsusue ${ }^{1}$ \\ ${ }^{1}$ Department of Orthopaedic Surgery, Shiga University of Medical Science, Tsukinowa-cho, Seta, Otsu, Shiga, Japan
}

\begin{abstract}
Study design: A case report.
Setting: Department of Orthopaedic Surgery, Shiga University of Medical Science, Japan.

Patient: A 13-year-old woman presented progressive weakness in the lower extremities, with predominance on the right. Magnetic resonance (MR) imaging revealed a huge syrinx. The patient also showed scoliosis, cleft palate, hearing impairment, excessive sweating, hairiness, dural ectasia, and malformation of the skull.
\end{abstract}

Method and objectives: We treated a very rare case of Arnold-Chiari syndrome, which presented with flaccid paralysis. Methods of differential diagnosis and suitable treatment are discussed.

Results and conclusion: Both the syrinx and muscle strength were quickly improved following placement of a syringo-peritoneal (S-P) shunt, after which the patient recovered the ability to walk. However, transient hypesthesia in the right hand occurred after the operation. The syrinx around the conus was thought to play a crucial role in the etiology of the patient case, which showed unique symptoms.

Spinal Cord (2004) 42, 541-544. doi:10.1038/sj.sc.3101607; Published online 27 April 2004

Keywords: syringomyelia; Arnold-Chiari syndrome; dural ectasia; progressive paralysis; S-P shunt

\section{Introduction}

We treated a rare case of Arnold-Chiari syndrome, which showed flaccid paralysis in the lower extremities. The patient also had scoliosis, cleft palate, hearing impairment, excessive sweating, hairiness, dural ectasia, and malformation of the skull. Following application of a syringo-peritoneal (S-P) shunt, acceptable results were achieved within a short period of time.

\section{Case report}

The patient was a 13-year-old female, with a chief complaint of muscle weakness in both lower limbs.

Family history: The mother and 2 younger sisters suffered from hearing impairments.

Past history: The patient was delivered using vacuum extraction without asphyxia at 42 weeks of gestation. She was found to have a cleft lip, cleft palate, and hearing impairment, for which she underwent surgery at the ages of 1 month, 2 years, and 3 years, respectively. Present illness: Muscle weakness in the right lower extremity became apparent in February 2000 and the patient

*Correspondence: T Mimura, Department of Orthopaedic Surgery, Shiga University of Medical Science, Tsukinowa-cho, Seta, Otsu, Shiga 520-2192, Japan came to our outpatient clinic on April 18. Soon thereafter, muscle weakness in both lower extremities progressed rapidly and she was admitted to our hospital on May 22, at which time she was also suffering from headache.

Findings on admission: The patient was $142 \mathrm{~cm}$ tall and weighed $42 \mathrm{~kg}$. Excessive sweating and hairiness were recognized over her entire body. There were no abnormal findings in a peripheral blood analysis. Sensory testing, muscle strength, and reflexes in the upper extremities were neurologically normal, whereas incomplete paralysis and hypo-tendon reflexes were seen in the lower extremities. The patient could not walk by herself. According to the manual muscle test (MMT), the extensor hallucis longus was $1 / 5$, flexor hallucis longus was $1 / 5$, quadriceps femoris was $4 / 5$, tibialis anterior was $2 / 5$, and gastrocnemius was $2 / 5$. There was also sensory disturbance (hypesthesia and hypalgesia) in both lower extremities from L4 to S1, with predominance in the right side. A slight deep sensation difficulty was also recognized in both lower extremities. Hypesthesia and hypalgesia were seen from the Th12 to Th6 areas of the trunk. Further, slight urinary incontinence appeared after admission. 
a

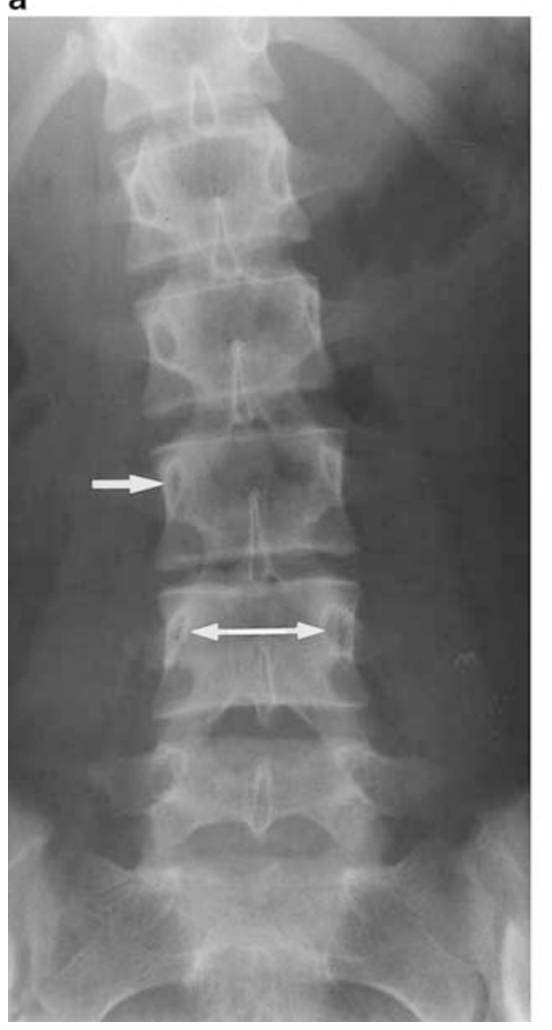

b



Figure 1 (a) Anteroposterior view of lumbar spine on X-ray image. An expansion of the interpediculate distance and a thinning of the pedicle are demonstrated. (b) Lateral view of the lumbar spine on X-ray image. A scalloping of the vertebral body and enlarged root exit foramina are demonstrated

a

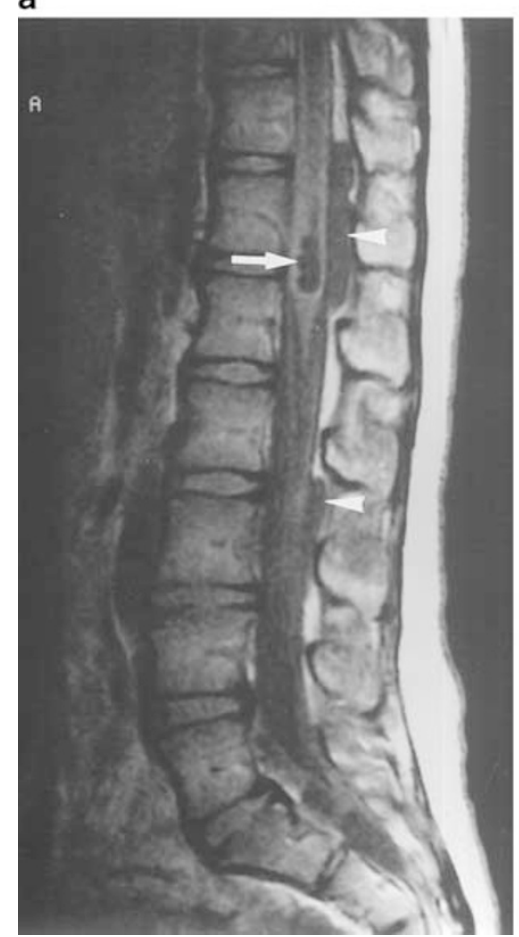

b

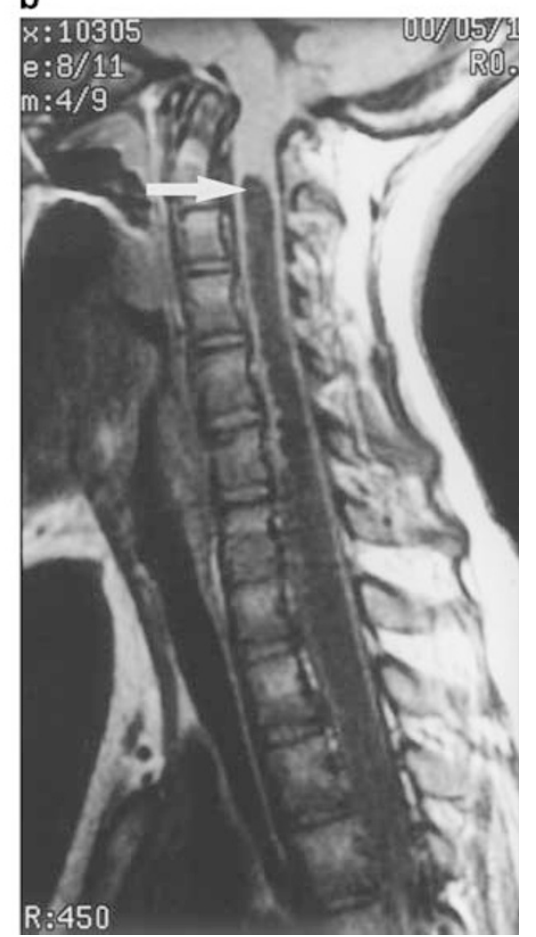

Figure 2 (a) MR imaging of lumbar spine. It revealed a syrinx of the conus and dorsal arachnoid diverticula (T1-weighted image). A high-intensity area around the syrinx of the conus level is also demonstrated. (b) MR imaging of cervical spine (T1-weighted image). The syrinx is extending from the upper cervical spine to the conus 


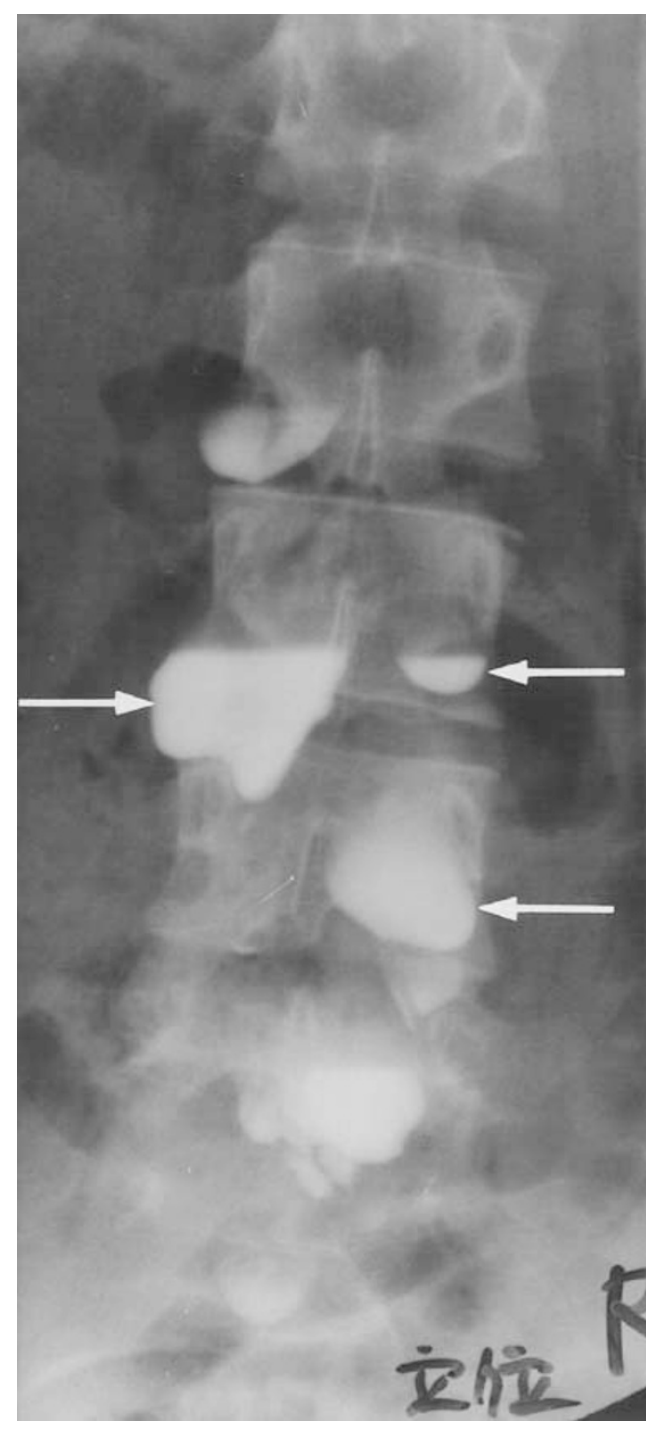

Figure 3 Myelography. It demonstrates multiple dural ectasia

Radiological investigations: Single curve scoliosis of the thoracic spine $\left(\mathrm{Cobb}\right.$ angle $27^{\circ}$ ), and expansion of the interpediculate distance and thinning of the pedicle of the lumbar supine were seen (Figure 1a). In addition, X-ray images revealed a scalloping deformity of the dorsal cortex and enlarged root exit foramina of the lumbar spine (Figure 1b). A flat skull and a basilar impression were also recognized. As for the pelvic bone, Risser's sign was grade 1 .

MR imaging of the thoracolumbar spine level showed a huge syrinx of the conus and dorsal arachnoid diverticula $^{1}$ (Figure 2a), while a high-intensity area around the syrinx was also revealed. This huge syrinx arose from the upper cervical spine through the conus (Figure 2b). Further, the septum of the spinal cord was partly recognized at the thoracic vertebral level.

Both myelography and computed tomography (CT) myelography imaging clearly demonstrated the multiple dural ectasia (Figures 3, 4).

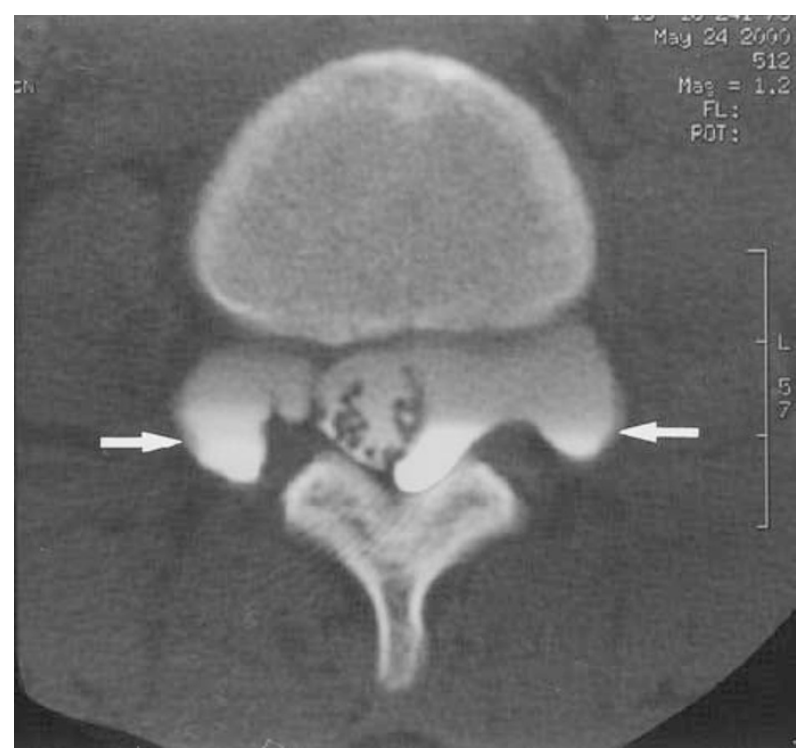

Figure 4 CT myelography. It clearly reveals the dural ectasia

According to these findings, we considered that the symptoms were due to syringomyelia, especially around the conus, and the patient underwent an S-P shunt procedure.

Operative findings: We performed a right hemilaminectomy of C7 and Th1, and found the dorsal root of C8. The S-P shunt was a tube made for lumbar-peritoneal (L-P) shunting, with an inside diameter of $0.7 \mathrm{~mm}$, and was placed while spinal cord-evoked potential (SCEP) monitoring was carried out.

Postoperative process: Liquor leakage was observed from the operative wound. However, it was stopped by continuous drainage from the lumbar spine 16 days after the operation. Muscle strength was markedly improved after surgery and the patient was able to regain her ability to walk, although transient hypesthesia in the right hand occurred after the operation. At 1 month following surgery, follow-up MR imaging revealed that both the syrinx at the conus and spinal cord swelling had diminished (Figure 5). The portion of the syrinx that was extended into the cervicothoracic level was also reduced, however, dural ectasia remained.

\section{Discussion}

In the present patient, we suspected a hereditary disease because of the family history of hearing impairment. For a differential diagnosis we considered Goldenhar syndrome $^{2}$ (oculo-auricular-vertebral dysplasia) and Taybi syndrome ${ }^{3}$ (a syndrome with hearing impairment, flat face, and cleft palate, etc.) but the criteria were insufficient.

Fattori et $a l^{4}$ defined dural ectasia as 'enlargement of the neural canal' in his thesis. It has also been reported that syringomyelia ${ }^{5,6}$ is often combined with scoliosis, while the combination of scoliosis and dural ectasia is rare according to Barnes et $a l^{7}$ and Schwend et al. ${ }^{8} \mathrm{In}$ addition, dural ectasia combined with Marfan syndrome 


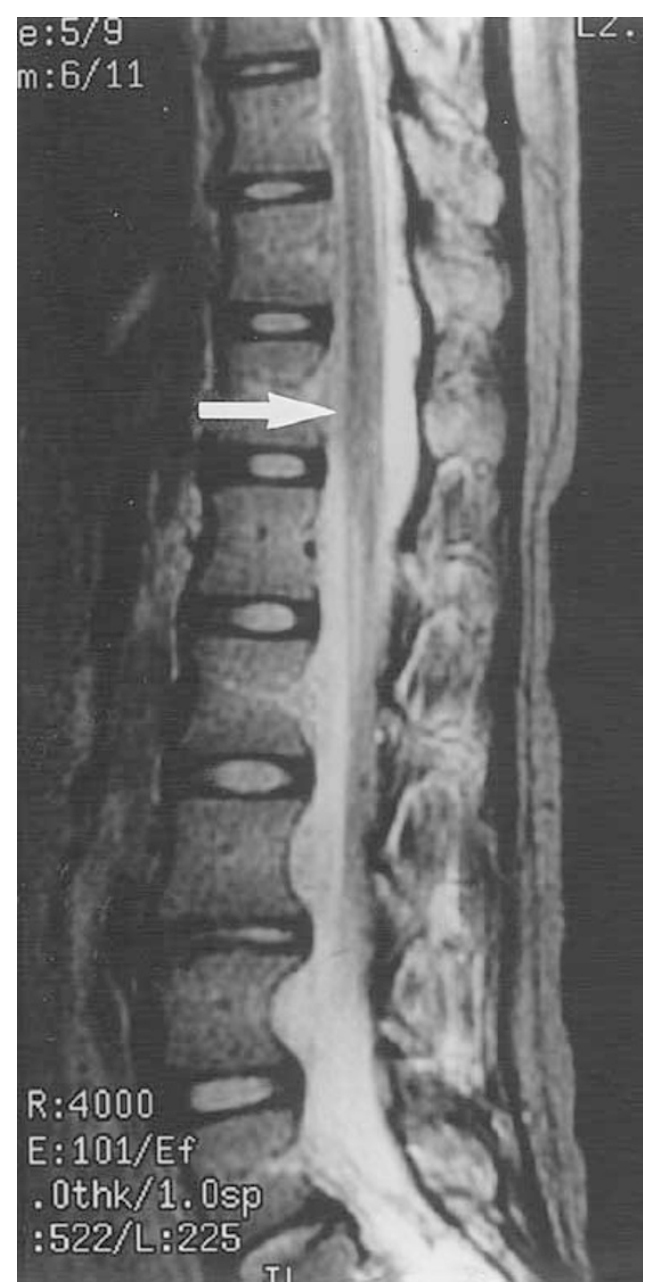

Figure 5 Postoperative MR imaging of lumbar spine (T2weighted image). It shows reduction of the syrinx and spinal cord swelling, as compared to preoparative findings

and neurofibromatosis type 1 as well as ankylosing spondylitis has been reported. However, to the best of our knowledge, there is no report comparable to the present case.

Our patient showed unique symptoms, such as progressive muscle weaknesses in only the lower extremities and a huge syrinx that extended from the upper cervical spine to the conus level. However, there were no symptoms in her upper extremities. To understand these unique features, we focused on the lumbar syringomyelia. We found a high-intensity area in T1weighted MR imaging around the syrinx of the conus level, which we considered to be caused by damage to the conus by the syrinx, such as from its expansion. We felt that the syrinx played a crucial role in the symptoms, because the shunt procedure achieved good results.

In general, foramen magnum decompression or a shunt method is employed during surgery for syringomyelia ${ }^{9}$. Shunts utilized include a syringo-subaracnoid (S-S) shunt, ${ }^{10,11}$ S-P shunt, ${ }^{12,13}$ and a ventriculoperitoneal (V-P) shunt. ${ }^{14}$ Since the patient demonstrated rapid progressive muscle weakness, we selected a shunt procedure to achieve a quick recovery and employed an S-P shunt rather than an S-S shunt, because of the existence of dural ectasia at the level of the lumbar spine. Since the syrinx had extended from the upper cervical spine to the conus, we selected the lower cervical spine level as the shunting point, where the syrinx was largest. Further, we were able to avoid touching the conus directly, which we considered would cause severe damage. To guard against exacerbation of the postoperative scoliosis, a hemilaminectomy and myelotomy in the dorsal site were chosen as low invasive techniques. In the present patient, surgical treatment achieved good results in a short period of time. Taking into consideration the pathogenesis of Arnold-Chiari malformation, foramen magnum decompression may be needed in the future.

\section{References}

1 Taveras JM. Neuroradiology, 3rd edn. Williams \& Wilkins: Massachusetts, 1996, pp 850-857.

2 Goldenhar M. Associations malformatives de l'oeil et de l'oeille; en particulier syndrome; dermoide epibulbaireappendices auriculaires fistula auris congenital et ses relations avec la dysostose mandibulofaciale. J Genett Hum 1952; 1: 243-282.

3 Taibi H. Generalized skeletal dysplasia with multiple anomalies. A note on Pyle's disease. Am J Roentgenol 1962; 88: 450-457.

4 Fattori R et al. Importance of dural ectasia in phenotypic assessment of Marfan's syndrome. Lancet 1999; 354: 910-913.

5 Barnett HJM et al. Syringomyelia, WB Saunders: Philadelphia, 1973, pp 3-123.

6 Gardner WJ. Hydrodynamic mechanism of syringomyelia; its relationship to myelocele. J Neurol Neurosurg Psychiatry 1965; 28: 247-259.

7 Barnes PD et al. Atypical idiopathic scoliosis; MR imaging evaluation. Radiology 1993; 186: 247-253.

8 Schwend RM et al. Childhood scoliosis; clinical indication for magnetic resonance imaging. J Bone Joint Surg ( Am) 1995; 77-A: 46-53.

9 Hida K et al. Surgical indication and results of foramen magnum decompression versus syringo-subarachnoid shunting for syringomyelia associated with Chiari I malformation. Neurosurgery 1995; 37: 673-679.

10 Padovani R, Cavallo M, Gaist G. Surgical treatment of syringomyelia: favorable results with syringosubaracnoid shunting. Surg Neurol 1989; 32: 173-180.

11 Tator $\mathrm{CH}$, Mequro K, Roward DW. Favorable results with syringo-subarachnoid shunts for treatment of syringomyelia. J Nuerosurg 1982; 56: 517-523.

12 Barbaro NM et al. Surgical treatment of syringomyelia. Favorable results with syringoperitoneal shunting. J Neurosurg 1984; 61: 531-538.

13 Ogilvy CS, Borges LF. Treatment of symptomatic syringomyelia with a ventriculoperitoneal shunt: a case report with magnetic resonance scan correlation. Neurosurgery 1988; 22: 748-750.

14 Philopon $\mathbf{J}$ et al. Treatment of syringomyelia by syringoperitoneal shunt. Acta Neurochir 1988; 43(Suppl): 32-34. 